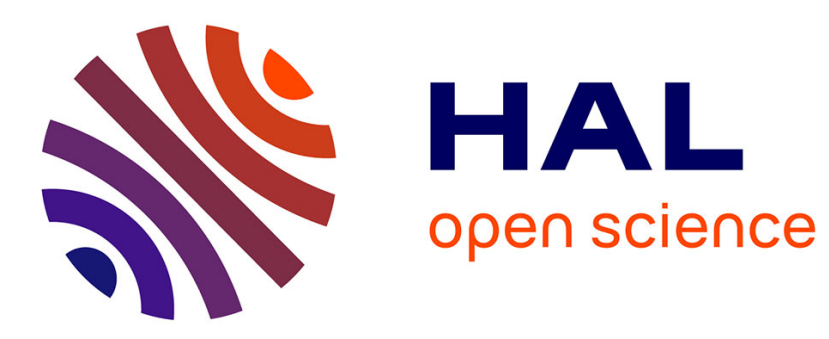

\title{
Coordination-Driven Syntheses of Compact Supramolecular Metallacycles toward Extended Metallo-organic Stacked Supramolecular Assemblies
}

Christophe Lescop

\section{To cite this version:}

Christophe Lescop. Coordination-Driven Syntheses of Compact Supramolecular Metallacycles toward Extended Metallo-organic Stacked Supramolecular Assemblies. Accounts of Chemical Research, 2017, 50 (4), pp.885-894. 10.1021/acs.accounts.6b00624 . hal-01485642

\section{HAL Id: hal-01485642 \\ https://hal.science/hal-01485642}

Submitted on 2 Oct 2017

HAL is a multi-disciplinary open access archive for the deposit and dissemination of scientific research documents, whether they are published or not. The documents may come from teaching and research institutions in France or abroad, or from public or private research centers.
L'archive ouverte pluridisciplinaire HAL, est destinée au dépôt et à la diffusion de documents scientifiques de niveau recherche, publiés ou non, émanant des établissements d'enseignement et de recherche français ou étrangers, des laboratoires publics ou privés. 


\title{
Coordination-driven Syntheses Of Compact
}

\author{
Supramolecular Metallacycles Toward Extended
}

\section{Metallo-Organic Stacked Supramolecular}

\author{
Assemblies.
}

Christophe Lescop

"Institut des Sciences Chimiques de Rennes", UMR 6226- CNRS, Université de Rennes 1, Campus de Beaulieu, 35042 Rennes Cedex, France. and INSA de Rennes, 20 Avenue des buttes de Coësmes, 35708 Rennes France

CONSPECTUS : 


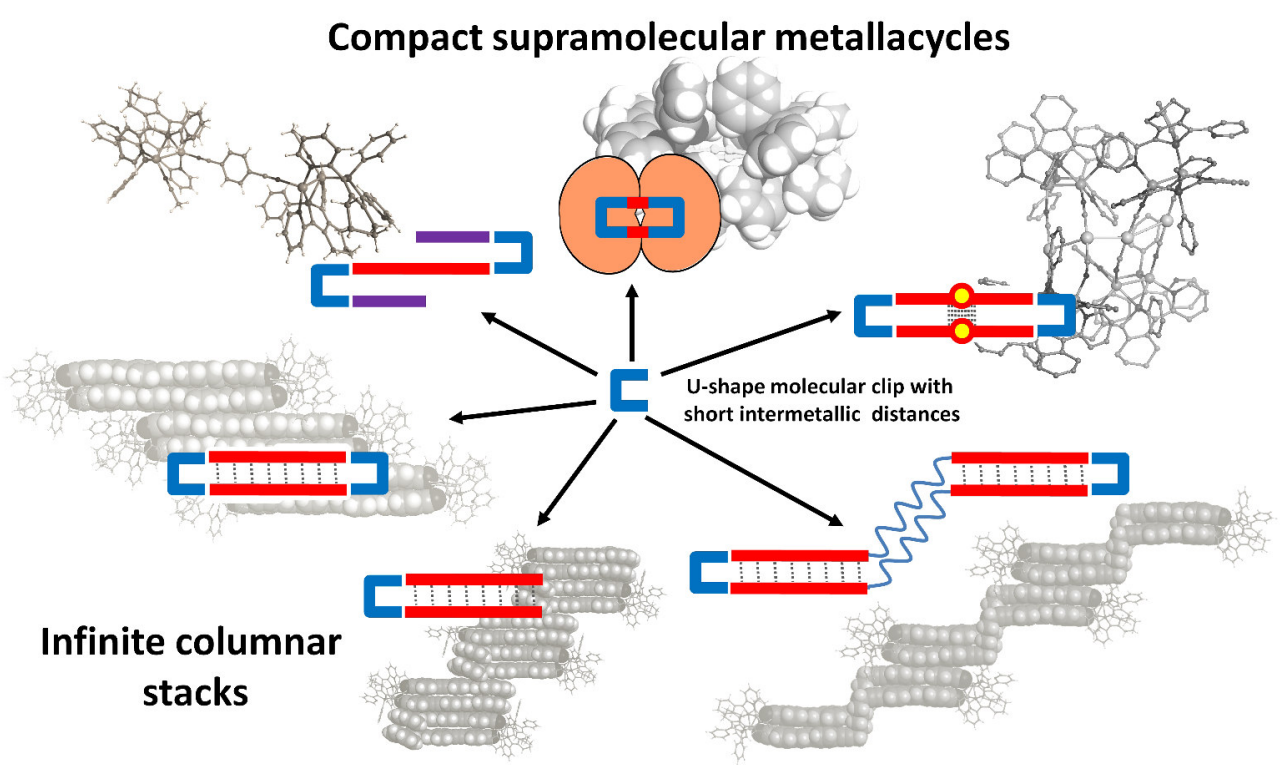

One important concept associated with supramolecular chemistry is supramolecular selfassembly which deals with the way discrete individual components interact via intermolecular interactions in order to build, upon their spontaneous association, high order functional assemblies. The accumulation of these very simple and localized noncovalent interactions (such as H-bonding, dipole-dipole, hydrophobic/hydrophilic, van der Waals, $\pi$ - $\pi$, $\pi$-CH, etc.) is ubiquitous in the complexity of natural systems (such as DNA, proteins, membranes, micelles, etc.). It can also be transposed to the directed synthesis of intricate artificial scaffolds which have anticipated geometries and properties.

Among the synthetic strategies based on this concept, coordination-driven supramolecular chemistry uses the robust, reversible and directional metal-to-ligand coordinative bond to build discrete metallo-supramolecular architectures. Within the last two decades, coordination-driven supramolecular chemistry has proved to be one of the most powerful contemporary synthetic approaches and has provided a significant number of increasingly complex supramolecular assemblies which have predetermined sizes and geometries. While much focus has been devoted to architectures bearing internal cavities for host-guest chemistry or to generate specific 
reactivity, particular attention can also be paid to compact supramolecular assemblies given that their specific structures are characterized by peculiar synthetic guiding rules as well as by alternative long range self-assembling properties. The present account describes how a preassembled $\mathrm{Cu}^{\mathrm{I}}$ bimetallic clip bearing short intermetallic distances can be used as a U-shape molecular clip to give general and versatile access to a large variety of original compact supramolecular metallacycles. When this $\mathrm{Cu}^{\mathrm{I}}$ precursor is reacted with various cyano-capped ditopic linkers that have increasing lengths and complexities, specific effects guiding the selective and straightforward syntheses of such compact supramolecular objects are highlighted. Whereas a subtle compromise between the length of the ditopic linkers and the steric bulk of the molecular clip appears to be a purely stereo-geometric preliminary parameter to master, lateral interlinker interactions $(\pi-\pi$ stacking interactions or aurophilic interactions depending on the nature of the internal cores of the linkers) can circumvent these constraints regardless of the length of the linkers and allow the selective formation of new compact supramolecular structures.

Generally, such derivatives presented a strong tendency to self-assemble in the solid state due to inter-supramolecule interactions. This approach thus opens a new door toward molecular materials having an attractive solid state structure for potential applications related to charge carrier mobility and luminescence properties. These compact supramolecular assemblies can therefore be considered as original secondary binding units directing the predictive preparation of such extended networks. The on-purpose design of original building blocks bearing specific cores allowed the formation of new compact supramolecular metallacycles such as 'U-shape' $\pi$ stacked assemblies or 'pseudo double paracyclophanes'. Similarly, the control of the secondary 
structure of one-dimensional coordination polymers alternating $\pi$-stacked compact supramolecular metallacycles was also conducted.

The results that are discussed in the present account illustrate how the rational design of both pre-assembled polymetallic precursors bearing short intermetallic distances and ditopic linkers capable to induce cumulative lateral weak interactions can implement the general synthetic guiding rules of coordination driven supramolecular chemistry. This opens perspectives to use such compact supramolecular assemblies as secondary building blocks for the design of longrange organized functional molecular materials that have predictable architectures and targeted properties.

\section{INTRODUCTION}

Coordination-driven supramolecular self-assembly has emerged in the last decade as one of the most powerful contemporary synthetic strategies and has provided increasingly intricate and functional molecular assemblies. ${ }^{1-6}$ It has allowed easy syntheses of unprecedented molecular architectures that would have been attainable only with immense difficulty using organic chemistry procedures. Key design principles were well-established in early works and have highlighted the importance of dynamic non-covalent interactions between the metal centers and multitopic linkers having suitable geometries to allow selective synthesis of targeted supramolecular assemblies. These initial paradigms have been regularly implemented thanks to constant advances in synthetic efforts and this has given access to original architectures with increased structural complexity such as low symmetry supramolecular assemblies ${ }^{7-9}$ and new functionalities. ${ }^{10-12}$ 


\section{a) Hollow Metallacycle}

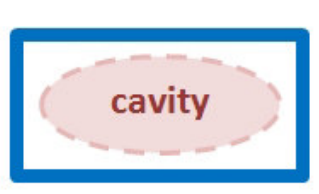

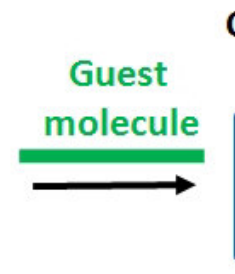

Compactly 'Filled' Metallacycle

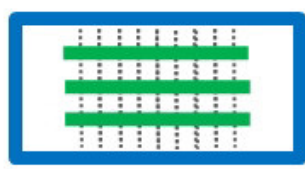

$\uparrow$

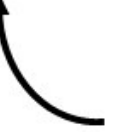

b) Compact Metallacycle

:1:1:1:!

Weak intramolecular interactions

Figure 1. a) Hollow metallacycle and 'compactly filled' metallacycle and b) compact metallacycle.

In a deliberate synthetic approach toward discrete supramolecular structures bearing internal cavities, coordination-driven supramolecular self-assembly reactions have supplied an overwhelming number of hollow two-dimensional metallacycles (Figure 1a) or threedimensional metallacages that bear valuable host-guest properties and reactivities. ${ }^{1-6,13-15}$ Many of these hollow scaffolds have been used as molecular containers to confine selected guestmolecules affording, in-fine, 'compactly filled' supramolecular assemblies (Figure 1a) bearing internal stacked aggregates. In these cases, extended $\pi$-conjugated systems ${ }^{16-18}$ and $\mathrm{d}^{8}$ or $\mathrm{d}^{10}$ metal complexes ${ }^{19-20}$ have been more frequently used as guest molecules taking advantage of, respectively, non-covalent $\pi-\pi$ interactions or metallophilic interactions to support the confinement of the individual molecules within the cavities and/or to confer to these stacked assemblies specific properties such as charge mobility or luminescent behaviors.

In comparison, compact coordination-driven supramolecular architectures in which no internal cavities are observed (Figure $1 b$ ) have received less attention. Nevertheless, such derivatives can be considered as a model of 'compactly filled' supramolecular assemblies in which non-convalent 
interactions are forced between the wall of the polytopic linkers used to build this original class of derivatives. In this account, a general coordination-driven supramolecular approach to compact two-dimensional metallacycles is outlined, highlighting specific synthetic rules to such derivatives and the crucial role played by lateral interlinker interactions in the selectivity of these syntheses.

\section{THE CHOICE OF THE PRE-ASSEMBLED MOLECULAR CLIP}

In order to prepare compact cyclic supramolecular assemblies, different synthetic alternatives have been reported. One approach using hydrogen bonding should be briefly mentioned, resulting from the co-crystallization of (4-pyridyl)-capped ditopic $\pi$-conjugated systems with building blocks, such as resorcinol, bearing H-bond donors closely located in a parallel convergent orientation (Figure $2 \mathrm{a}$ ). ${ }^{21}$ In the resulting assemblies, the $\pi$-walls of the ditopic linkers are arranged in the solid state in a face-to-face arrangement with short intramolecular contacts, which made it possible to perform quantitative stereoselective and regioselective [2+2] photo-dimerization reactions.

Approaches in which coordination bonds are used to build compact supramolecular assemblies can be arranged in two categories. 

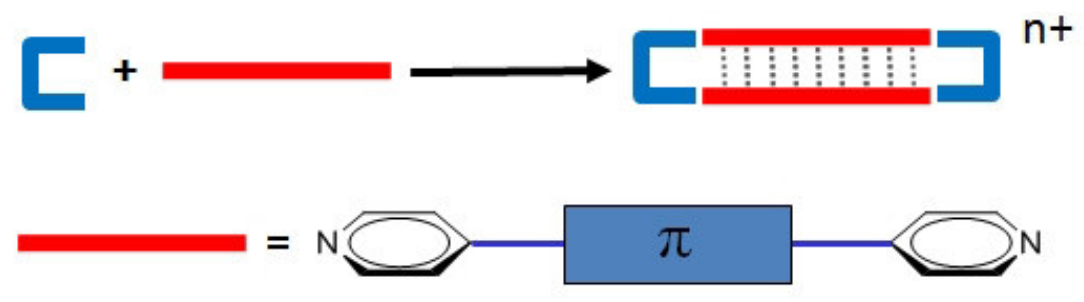

: 'U-shape' molecular clip ;

\section{: ditopic linker}

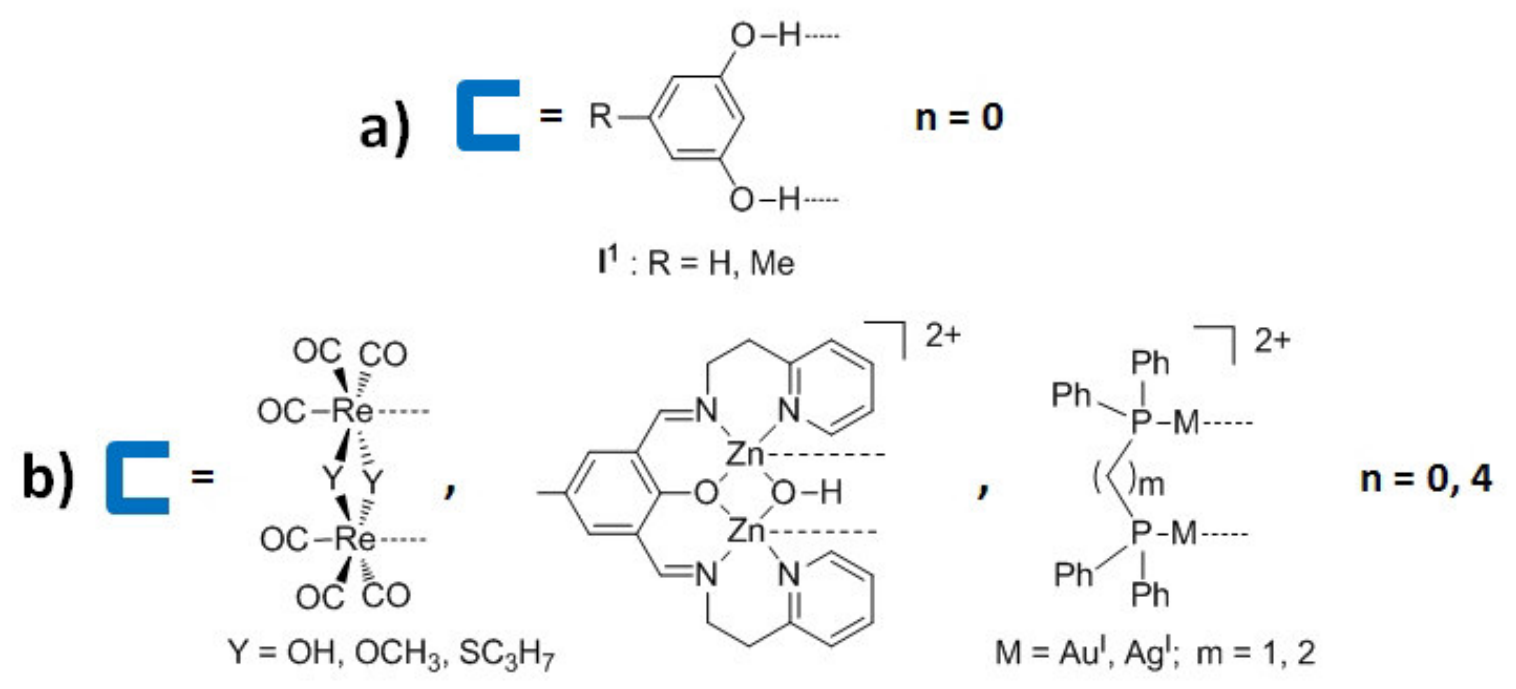

Figure 2. Synthesis of compact supramolecular assemblies using a) H-bond donors, b) 'U-shape' bimetallic molecular clips.

The first approach (the so-called Weak Link Approach) relies on the use of hemilabile linkers bearing heteroditopic donor chelating moieties from which different stereo-electronic properties of the coordination sites arise. ${ }^{22,23}$ Upon regioselective coordination on selected metal centers which have suitable coordination geometries, compact supramolecular metallacycles (Figure 3) having no internal cavities and intralinker interactions have been characterized. Interestingly, due to the hemilability of the assembling ligands, these compact structures can be specifically and 
reversibly modulated to hollow structures via coordination of ancillary ligands to the metal centers. $^{22}$
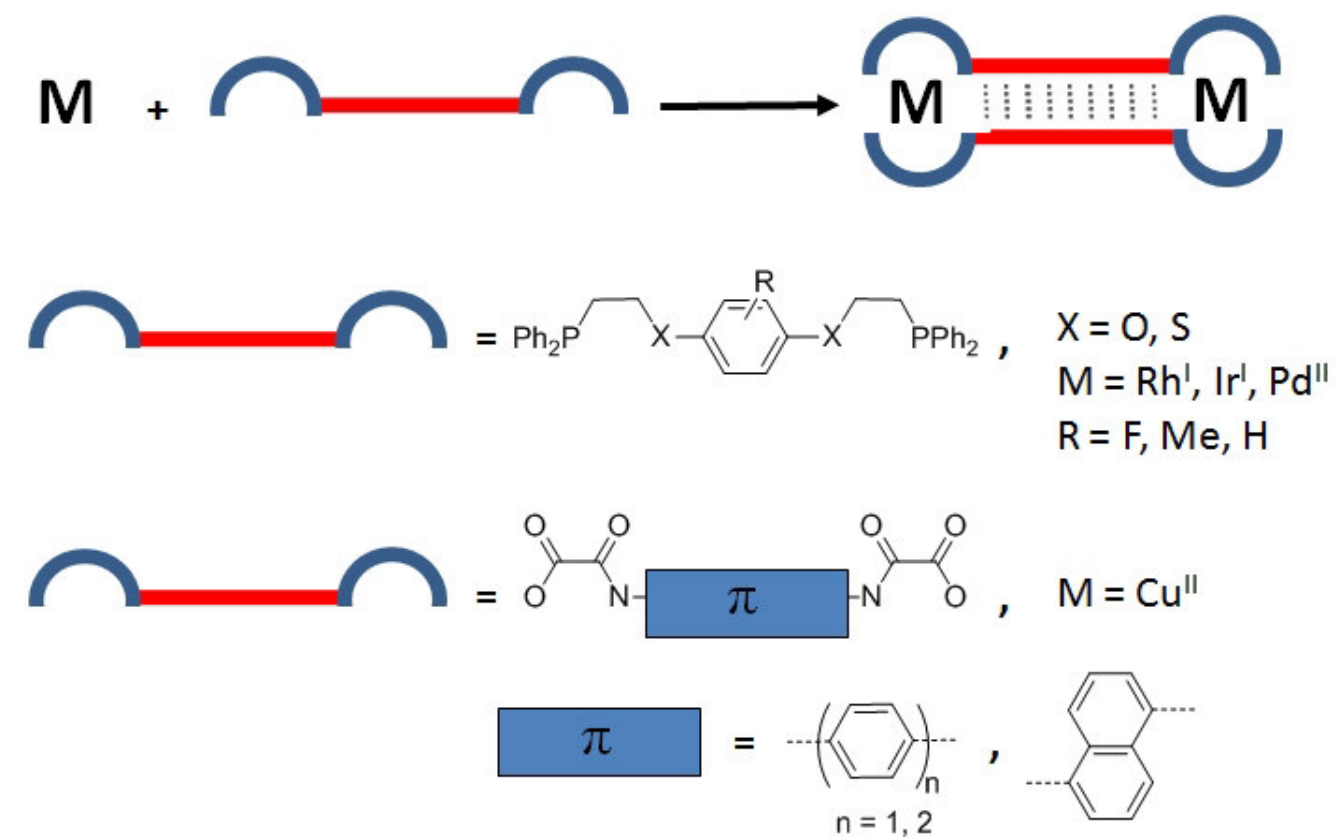

Figure 3. Synthesis of compact supramolecular metallacycle using heteroditopic chelating moieties.

However, the more commonly used coordination-driven synthesis approach toward compact supramolecular metallacycles relies on the reaction of pre-assembled bimetallic molecular clips with ditopic linkers ${ }^{24}$ obeying the general synthetic guiding rules of the 'directional bounding approach'. ${ }^{1}$ To give access to the targeted supramolecular metallacycles, bimetallic molecular clips bearing two cis-coordination labile sites (conferring to these molecular clips a 'U-shape' geometry, figure 2) and short intermetallic distances have been reacted with linear ditopic linkers to drive the selective formation of self-assembled structures without internal cavities. Preassembled polymetallic stable building blocks that satisfy these requirements are scarce (Figure 2b): $\operatorname{Re}^{\mathrm{I}}$ complexes bridged by hydroxo or alkoxo, ${ }^{25}$ sulfide, ${ }^{26}$ bipyrimidine or 
bis(benzimidazolate ${ }^{27}$ ligands, $\mathrm{Zn}^{\mathrm{II}}$ derivatives assembled by $\mu-\mathrm{O}$ atoms ${ }^{21}$ and $\mathrm{Ag}^{\mathrm{I}}$ or $\mathrm{Au}^{\mathrm{I}}$ stabilized by diphosphine ligands ${ }^{28}$ have provided compact supramolecular metallacycles based on (4-pyridyl)-capped $\pi$-conjugated linkers (Figure $2 \mathrm{~b}$ ). Within these compact derivatives and as a result of their coordination on closely located metal centers, intramolecular $\pi$ - $\pi$ interactions have been observed between the $\pi$-walls of the assembled linkers.

In the course of our study of the coordination chemistry of the 2,5-bis(2-pyridyl)phosphole ligand 1 (Figure $4 \mathrm{a}$ ), we have characterized a series of $\mathrm{Cu}^{\mathrm{I}}, \mathrm{Ag}^{\mathrm{I}}, \mathrm{Pd}^{\mathrm{I}}$ and $\mathrm{Pt}^{\mathrm{I}}$ dimers stabilized by the formation of $\mathrm{N}, \mathrm{P}, \mathrm{N}$ chelates bearing bridging phosphane coordination mode which is a very unusual coordination mode in the family of the widely used phosphane ligands. ${ }^{29-31}$ Such a ligand framework, alternating pyridine and phosphole rings, still remains unique in coordination chemistry due to its general ability to stabilize polymetallic units via the formation of such a bridging phosphane coordination mode. ${ }^{32,33}$ Among the complexes obtained, the air stable $\mathrm{Cu}^{\mathrm{I}}$ bimetallic complex 2 (Figure $4 a)^{30}$ presents the constrained 'U-shape' geometry and short metalmetal distances (ca. $2.55 \AA$ ) required for coordination-driven supramolecular assembly of compact supramolecular metallacycles. Indeed, the coordination sphere of the $\mathrm{Cu}^{\mathrm{I}}$ ions bears two 'cisoid' labile acetonitrile ligands that can be potentially replaced by coordination of polytopic donor linkers. It is worth noting that the ligands $\mathbf{1}$ exhibit in the coordination sphere of the metal ions of $\mathbf{2}$ an hemilabile fluxional coordination in solution that has been assigned to a fast intermolecular exchange between the N,P,N and the P,N ligands (Figure 4b) involving coordinated and pendant pyridine groups. ${ }^{30}$ This feature confers to the derivative 2 a unique conformational adaptivity that facilitates its association with linkers that have various steric and electronic demands. 
a)

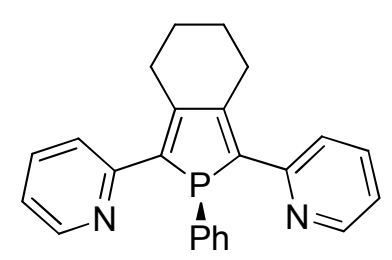

1

b)

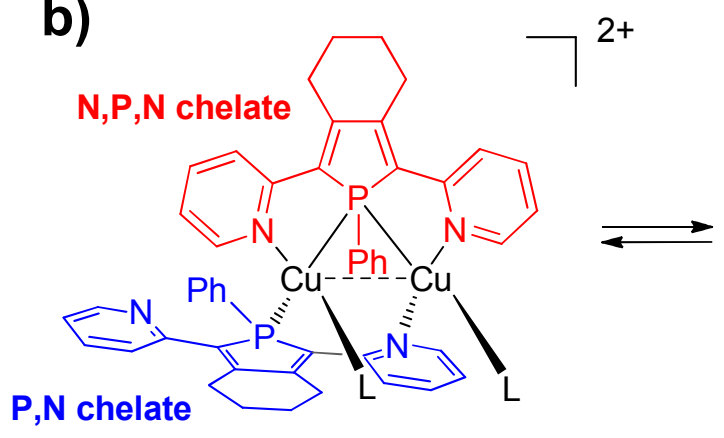

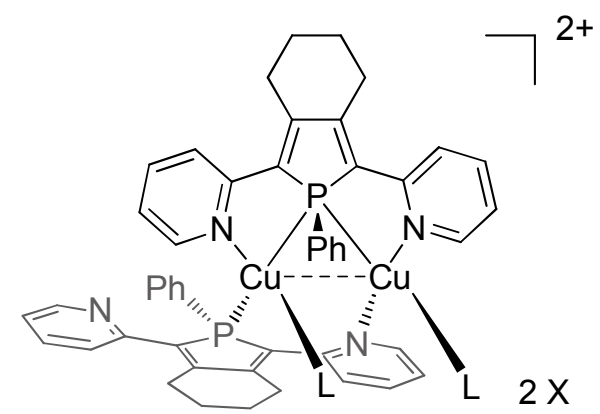

$2 \begin{aligned} & \mathrm{L}=\mathrm{CH}_{3} \mathrm{CN} \\ & \mathrm{X}=\mathrm{PF}_{6}^{-,}, \mathrm{BF}_{4}\end{aligned}$

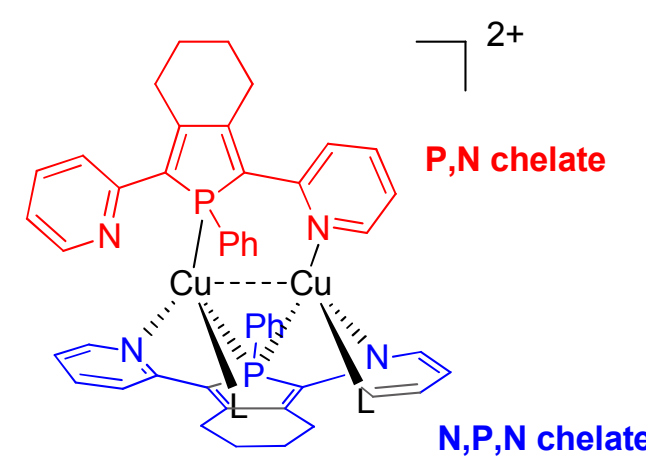

Figure 4. a) Molecular structure of the ligand $\mathbf{1}$ and of the U-shape bimetallic molecular clip 2; b) Hemilabile fluxional coordination behavior of the ligands $\mathbf{1}$.

\section{FORMATION OF COMPACT METALLACYCLES : REACTION OF THE MOLECULAR CLIP 2 WITH 'SHORT' DITOPIC LINKERS}

The reaction of $\mathbf{2}$ with 'short' ditopic linkers provided the perfect case-study to probe the reaction mechanisms and specific effects that rule elementary self-assembly processes leading to the formation of compact supramolecular metallacycles. The term 'short' is hereby used to define linkers 3-7 having only one, or no, structural group connecting the terminal cyano coordination functions within the core of the linkers (Figure 5a).

\subsection{Synthesis of small compact metallacycles : the 'sterical protection effect'}


First, reacting cyanide ion linker $\mathbf{3}$ with $\mathbf{2}$, a small dicationic tetranuclear compact metallacycle $\mathbf{8}$ was isolated in a high yield (Figure 5b). ${ }^{34}$ Despite the short length of this connecting anion, neither steric constraint nor short contact interaction have been observed between the two dimeric $\mathrm{Cu}_{2}(\mathbf{1})_{2}$ units and the two assembled cyano fragments. The $\mathrm{Cu}^{\mathrm{I}}$ intermetallic distance in these $\mathrm{Cu}_{2}(\mathbf{1})_{2}$ moieties in $\mathbf{8}$ is almost unchanged (ca. $2.56 \AA$ ) as the acetonitrile ligands of $\mathbf{2}$ are replaced by the cyano linkers 3 . The driving force leading to selective formation of this metallacycle at the expense of oligomeric or polymeric forms has been assigned to a 'sterical protection effect'. ${ }^{34}$ This effect relies on the shape and the steric hindrance of the $\mathrm{Cu}_{2}(\mathbf{1})_{2}$ units together with the rigidity of the parallel coordination position at the two $\mathrm{Cu}^{\mathrm{I}}$ sites that lead to a unique favorable self-assembling possibility a regioselective 'face to face' orientation of the $\mathrm{Cu}_{2}(\mathbf{1})_{2}$ moieties (Figure 5b). This effect is also observed along the formation of other small compact metallacycles resulting from the reaction of $\mathbf{2}$ with the azido $\mathrm{N}_{3}{ }^{-}$and tricyanomethanide $\mathrm{C}(\mathrm{CN})_{3}{ }^{-}$anions (acting in this last case as a ditopic linker with a cyano fragment left uncoordinated). ${ }^{34}$ It highlights the importance of the design of the assembling ligand $\mathbf{1}$ in such coordination-driven supramolecular processes toward compact metallacycles. Thus, a delicate balance between the steric congestion of the molecular clip scaffold and the length of the ditopic linkers appears to be a specific and general stereo-geometric parameter to consider in order to promote the selective and straightforward formation of discrete compact supramolecular metallacycles from simple ditopic linkers. 


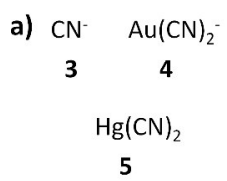

c)

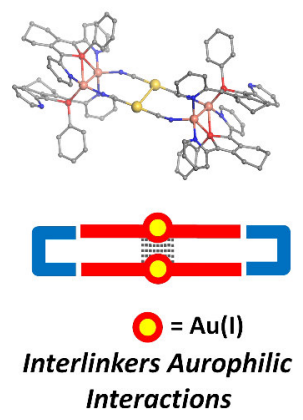

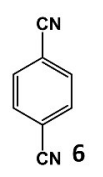

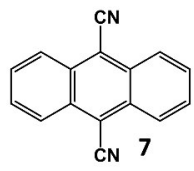

b)
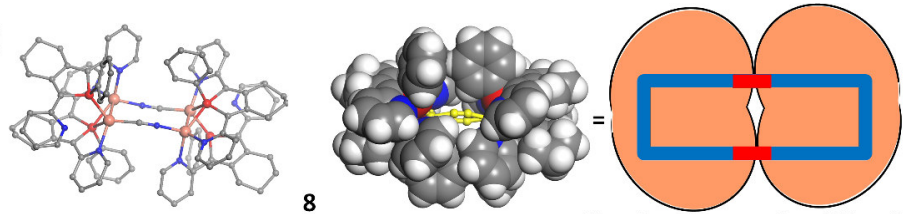

'Sterical Protection Effect'

d)

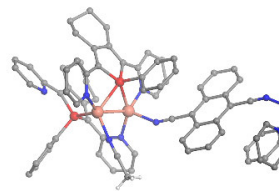

$7 a$

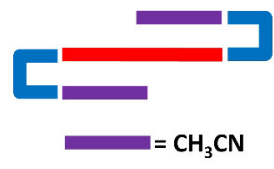

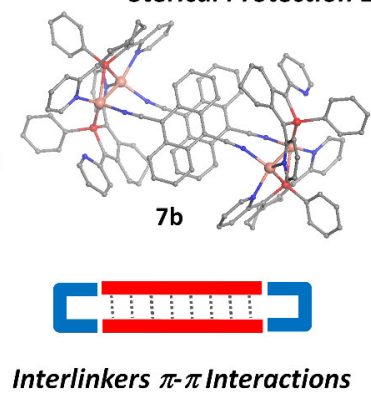

Figure 5. a) Molecular structure of linkers 3-7; X-ray crystal structure and schematic description of : b) the metallacycle 8 ('Sterical Protection Effect'); c) selected metallacycles based on the linker $\left.\left[\mathrm{Au}(\mathrm{CN})_{2}\right]^{-} \mathbf{4} ; \mathrm{d}\right)$ the open derivative $\mathbf{7 a}$ and the compact metallacycle $\mathbf{7 b}(\mathrm{H}$ atoms, counter-anions and solvent molecules are omitted for clarity).

\section{2 'Metal-rich' compact metallacycles : the role of the interlinker aurophilic interactions}

Directly related to this conclusion comes the assumption that increasing the length of the ditopic linker should impact the fate of the self-assembling processes conducted from the molecular clip 2. This was explored using linear gold(I) cyanide $\left[\mathrm{Au}(\mathrm{CN})_{2}\right]^{-} \mathbf{4}$ and mercury(II) cyanide $\mathrm{Hg}(\mathrm{CN})_{2}$ 5 as ditopic linkers. ${ }^{35}$ Along the reaction with $\mathrm{K}\left[\mathrm{Au}(\mathrm{CN})_{2}\right]$, pseudo-polymorphism was observed in the crystallization experiments, but in all cases compact discrete metallacycles were characterized (Figure 5c). ${ }^{35}$ In these assemblies, $\mathrm{Cu}^{\mathrm{I}}$ intermetallic distances remained unchanged (ca. $2.6 \AA$ ) compared to the precursor 2 while intramolecular $A u^{I}-A u^{I}$ short distances (d(Au-Au);

3.3-3.5 A) revealed stabilizing aurophilic interactions. Moreover, one of the pseudo-polymorph characterized presented a remarkable dimerization of these compact metallacycles (Figure 5c) thanks to a short $\mathrm{Au}^{\mathrm{I}}-\mathrm{Au}^{\mathrm{I}}$ aurophilic intermolecular interaction (d(Au-Au); ca. $3.1 \AA$ ). 
Conversely, as $\mathrm{Hg}(\mathrm{CN})_{2} \mathbf{5}$ was reacted with 2, various supramolecular architectures (compact metallacycle, oligomeric and polymeric species) were characterized concomitantly revealing that selective supramolecular coordination-driven synthesis was not achieved in this case. ${ }^{35}$ It is worth noting that, despite the fact that intermetallic $\mathrm{Cu}^{\mathrm{I}}$ distances are mostly unchanged, intermetallic $\mathrm{Hg}^{\mathrm{II}}-\mathrm{Hg}^{\mathrm{II}}$ distances in all these assemblies are too large for intramolecular metallophilic interactions. These observations revealed that, in and of themselves, neither the short intermetallic distance in the U-shape molecular clip 2 nor its steric congestion are the only decisive factors to be taken into account to drive selective syntheses of supramolecular compact supramolecular metallacycles. As the length of the ditopic linker used was increased, secondary interactions arising between the cores of the self-assembled homoditopic linkers turned out to play a major role to direct these supramolecular assembling processes.

The choice of the internal core composition of the ditopic ligand appears therefore to be important to promote the synthesis of compact metallacycles as it can induce stabilizing intramolecular interlinker interactions allowing selection of such architectures at the expense of open oligomeric or polymeric forms. This feature sets the synthetic approach to compact supramolecular metallacycles apart from those that lead to hollow supramolecular metallacycles as well as those conducted from traditional organic syntheses. Indeed in these last two cases, the nature of the core of the linkers usually have a negligible effect on the nature of the architectures obtained.

\subsection{Small $\pi$-stacked compact metallacycles : the crucial importance of the interlinker $\pi$ - $\pi$ interactions}


It is well identified that one of the most important general features guiding coordination-driven supramolecular syntheses is the possibility to set up robust, directional, but reversible coordinative bonds between the metal ions and the connecting ligands. This allows fast equilibrium between the starting materials and all the potential products, and induces an errorcorrection mechanism during the reaction resulting in the formation of the thermodynamically most stable species as a single product. Importantly, given that the ligands are varied, metalligand coordination bonds offer large possibilities of modulation of strengths and directionalities. In the case of the reaction of the derivative 2 with the inorganic ditopic linkers $3-5$, the substitution of the labile acetonitrile ligands carried by the $\mathrm{Cu}^{\mathrm{I}}$ centers of $\mathbf{2}$ is favorable as the anionic $\mathrm{CN}^{-}$fragments present a strong affinity with cationic $\mathrm{Cu}^{\mathrm{I}}$ ions. Conversely, the substitution of these acetonitrile ligands by the 'short' organic neutral cyano-capped linkers 6-7 (Figure 5a) afforded self-assembly reactions in which the exchanges between coordinated acetonitrile ligands and ditopic linkers were expected to be more balanced. The fate of the coordination-driven processes was then impacted providing additional clues about the factors ruling the formation of compact supramolecular metallacycles.

Ditopic linkers 6 and 7 have the same length (ca. $7.9 \AA$ A) but present different extents of their $\pi$ conjugated internal cores in terms of electronic and steric properties. Upon their reactions with 2, open supramolecular assemblies $\mathbf{6 a} / 7 \mathbf{a}$ (Figure $5 \mathrm{~d}$ ) were characterized together with the targeted compact metallacycles $\mathbf{6 b} / 7 \mathbf{b},,^{36,37}$ suggesting a sequential stepwise assembling process that could not be observed in the case of the linkers 3-5. In all these assemblies, intermetallic distances in the $\mathrm{Cu}_{2}(\mathbf{1})_{2}$ fragment are mostly unchanged. In the compact metallacycle structures $6 \mathbf{b} / 7 \mathbf{b}$, the $\pi$ conjugated moieties of the linkers are parallel with short intramolecular distances (below $3.5 \AA$ ) that are relevant for $\pi-\pi$ interactions. Importantly, the ratio observed between open 
supramolecular assemblies and compact metallacycles can be directly connected with the extent of the $\pi$-conjugated cores of the linkers $6 / 7$ : an excess of $\mathbf{6}$, bearing a simple central phenyl, was necessary to displace equilibrium to selectively afford the compact metallacycle 6a at the expense of the open assembly $\mathbf{6 b}$. Conversely, only a stoichiometric ratio was needed to selectively form the compact metallacycle $\mathbf{7 b}$ in which the strongest lateral $\pi-\pi$ interactions are observed. $^{36}$

Therefore, similar to the metallophilic interactions observed in the case of the reaction of $\left[\mathrm{Au}(\mathrm{CN})_{2}\right]^{-} 4$ (Figure $5 \mathrm{c}$ ), $\pi-\pi$ interlinker lateral interactions can also promote the formation of compact metallacycles. Since cyano-capped organic $\pi$-conjugated linkers are not expected to be much better ligands toward the $\mathrm{Cu}^{\mathrm{I}}$ metal centers of $\mathbf{2}$ than acetonitrile ligands, these observations point out how crucial these lateral interlinker interactions are in order to drive the selection of the compact metallacycle structure as the thermodynamically most stable product.

\section{FORMATION OF LARGE $\pi$-STACKED COMPACT METALLACYCLE AND THEIR SOLID STATE ORGANIZATION WITHIN INFINITE $\pi$-STACKED COLUMNS}

Cyano-capped organic $\pi$-conjugated linkers proved to be very attractive ligands to explore scale and limitation of this synthetic strategy toward compact supramolecular metallacycles. Beside the synthetic challenge, the formation of such supramolecular objects is also of interest in the field of $\pi$-conjugated molecular materials for optoelectronic devices. Indeed, one of the critical factors determining the performance of such devices is the long range supramolecular organization of the $\pi$-conjugated systems in the solid state since intermolecular interactions (such 
as the $\pi-\pi$ interactions governing the solid state aggregation of $\pi$-conjugated systems in extended networks) significantly alter the bulk material physical properties. ${ }^{38,39}$ Therefore, the understanding of all the hierarchical organization steps leading to $\pi$-stacked material is a major issue in this field. The gathering of two individual extended $\pi$-conjugated systems within compact supramolecular metallacycles (Figure $2 b$ ) supplies an attractive experimental tool to probe the effects forcing such isolated functional molecules to be locally matched in $\pi$-dimers before eventually becoming arranged in extended networks in the solid state.

Reaction of the $\mathrm{U}$-shape molecular clip $\mathrm{Cu}^{\mathrm{I}}$-clip 2 with various homoditopic $\pi$-conjugated linkers (Figure 6a) made it possible to introduce a large structural diversity in original $\pi$-stacked compact metallacycles (Figure 6b). ${ }^{37,40}$ Indeed, linkers of various lengths (up to $27.7 \AA$ ), different chemical compositions (oligo(para-phenylenevinylene)s OPVs, oligo(phenylene)s, oligo(phenylethynylene)s), and geometries (linear, angular) have been successfully involved in such reactions. In all these new compact metallacycles, obtained in good yields, the intermetallic distances of the $\mathrm{Cu}_{2}(\mathbf{1})_{2}$ units are unchanged (ca. $2.5 \AA$ ). Upon their assembly within these compact metallacycles, the $\pi$-walls of the ditopic linkers are parallel, arranged in an almost faceto-face relative orientation and present short interlinker distances (ca. $3.5 \AA$ ) relevant for $\pi$ - $\pi$ interactions. 
a)
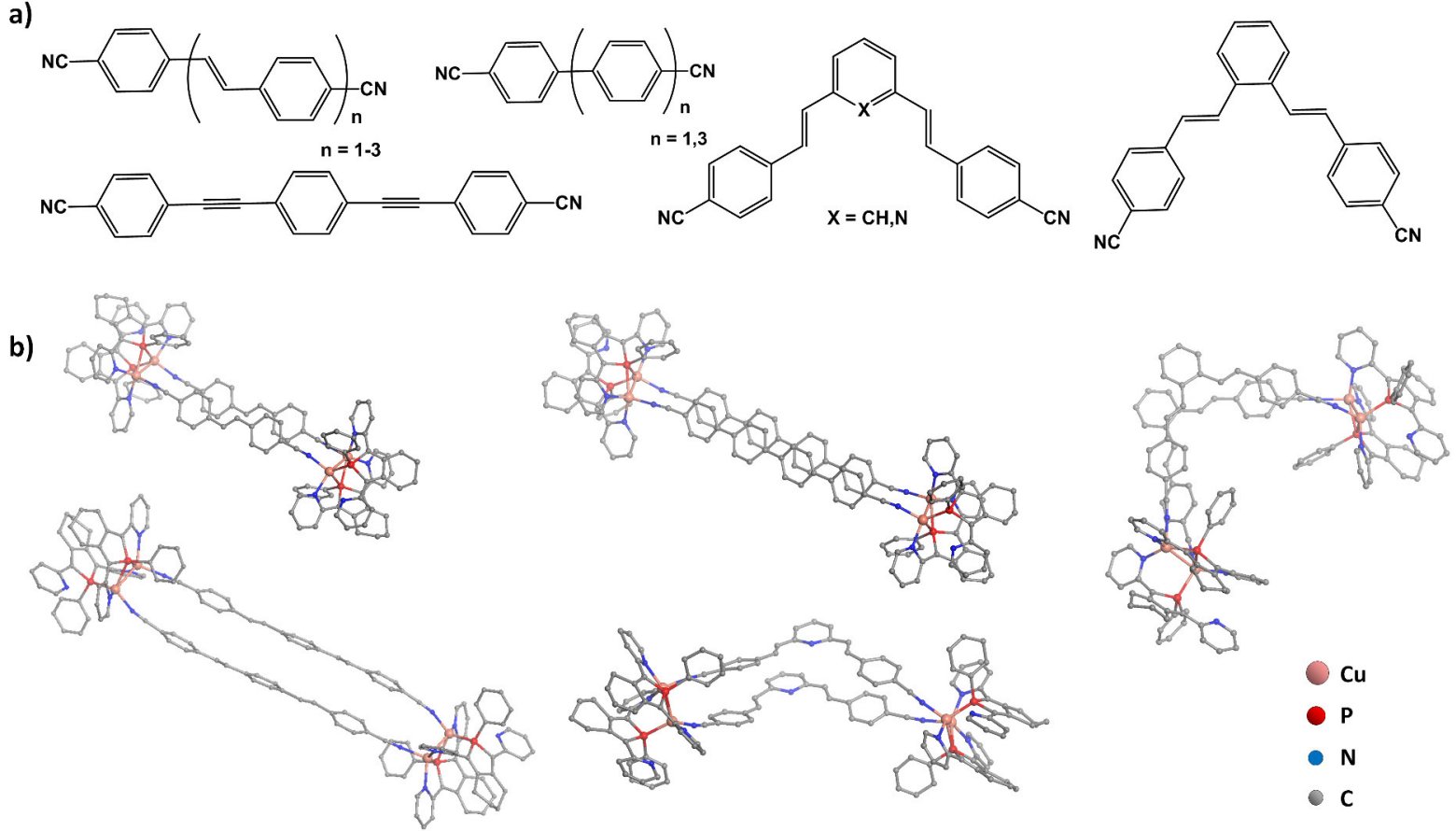

c)

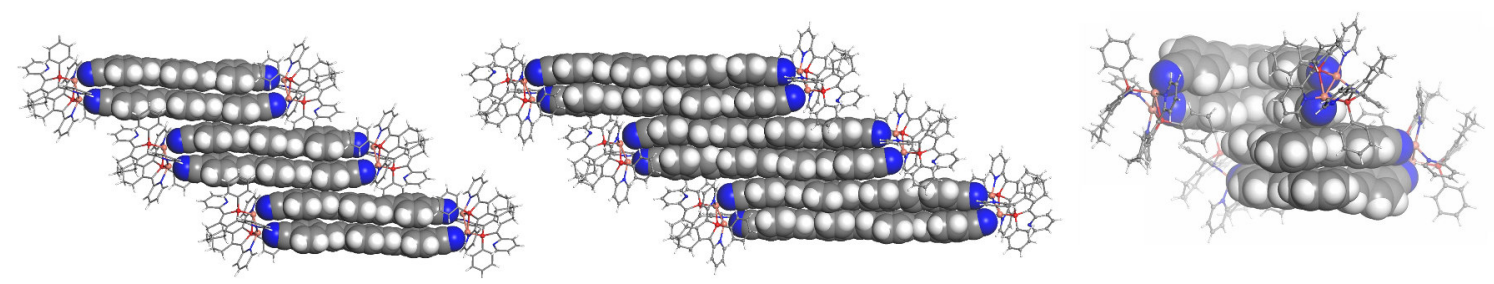

Figure 6. a) Molecular structure of the extended $\pi$-conjugated linkers; b) X-ray crystal structure of selected $\pi$-stacked tetracationic compact metallacycles; c) Views of selected solid state stacking patterns of $\pi$-stacked metallacycles : fragments of infinite $\pi$-stacked columns (for OPVbased linkers with $n=2$ and 3 respectively) and $\pi$-dimers (OPV-based linker bearing a central 1,2-substituted phenyl ring).

Remarkably, on increasing the length of the linear $\pi$-conjugated linkers, these derivatives selforganized in the solid state in infinite $\pi$-stacked columns (Figure $6 \mathrm{c}){ }^{37,40}$ In all cases, short intermolecular distances (ca. 3.1-3.5 $\AA$ ) between the $\pi$-walls of two neighboring supramolecules 
revealed parallel displaced intermolecular $\pi-\pi$ interactions. Conversely, the self-assembled $\pi-$ stacked compact metallacycles based on angular linkers were either isolated or formed $\pi$-dimers of metallacycles when the linkers were based, respectively, on a central 1,3-subtituted or 1,2 substituted 6-membered ring (Figure 6c). ${ }^{40}$

It is established that such a long range organization of functional $\pi$-systems favors charge-carrier mobility, a property that is necessary for molecular materials aimed to produce organic field effect transistors. In order to allow control over such solid state organization, a case-by-case sophisticated, time consuming and sometimes expensive molecular engineering of the organic $\pi$ systems is usually necessary. Hollow metallacycles (Figure 1a) have also been used to organize within their cavities $\pi$-systems in extended $\pi$-stacked networks. ${ }^{17-19}$ Nevertheless, sophisticated synthetic procedures are also needed in these cases. Conversely, from coordination-driven supramolecular syntheses based on U-shape molecular clip 2, a general and fast synthetic approach can be conducted toward such $\pi$-stacked molecular materials. Indeed, a versatile hierarchical organization of cyano-capped linear $\pi$-conjugated systems occurs first within $\pi$ stacked compact supramolecular metallacycles that in turn self-organize in the crystalline solid state in infinite $\pi$-stacked columns. The use of the bimetallic molecular clip 2 bearing short intermetallic distances and a rigid structure together with the hemilabile coordination behavior of the ligands $\mathbf{1}$ is therefore very valuable to conduct these selective syntheses. Nevertheless, in order to obtain efficient molecular materials for optoelectronic applications from these materials, several drawbacks still need to be overcome : these compact metallacycles are polycationic which might be a problem in the case of a molecular material targeting charge mobility. In addition, this three-dimensional organization observed in the crystalline solid state should be 
transferred on two-dimensional surfaces in order to allow the easy production and bulk property evaluation of the targeted devices, which is a task that still needs to be carried out.

Nevertheless, the large panel of ditopic cyano-capped $\pi$-conjugated systems successfully introduced in the $\pi$-stacked compact metallacycles described demonstrates the efficiency of this synthetic approach. This also supports the very important role played by the lateral interlinker interactions $(\pi-\pi$ interactions or aurophilic interactions) to drive these selective and straightforward syntheses. Derivative $\mathbf{2}$ therefore reveals to be a powerful synthetic tool to direct the assembly of unprecedented compact supramolecular objects.

\section{TOWARD ORIGINAL $\pi$-STACKED SUPRAMOLECULAR ASSEMBLIES}

\section{1 'U-shape' $\pi$-stacked supramolecular assemblies}

Indeed, the reaction of the U-shape molecular clip 2 with dissymmetric $\pi$-conjugated systems 812 bearing only one terminal nitrile coordination group (Figure 7a) afforded a new series of infinite columnar $\pi$-stacks : While derivative 2 did not react with benzonitrile, the ligand $\mathbf{8 , 9}$ bearing longer $\pi$-conjugated cores afforded selective formation of original 'U-shape' $\pi$-stacked supramolecular assemblies (Figure $7 \mathrm{a}$ ). ${ }^{41}$ This confirmed, if confirmation is still needed, how crucial the cumulation of lateral $\pi-\pi$ interactions is within these self-assembled structures to promote their formation. Functional extended $\pi$-conjugated fragments bearing large lateral planar and non-planar terminal units such a pyrene (10) and carbo[4]helicene $(\mathbf{1 1 , 1 2})$ have also been successfully reacted producing discrete $\pi$-stacked supramolecular aggregates. This highlights the large tolerance allowed in the structure of the terminal $\pi$-conjugated moieties along these self-assembly processes. Nevertheless, the bulkier carbo[6]helicene could not be 
gathered in such $\pi$-dimer, most probably due to a too large steric congestion. These 'U-shape' derivatives self-assembled in the solid state in head-to-tail dimers. ${ }^{41}$ As a result of a competition between $\mathrm{CH}-\pi$ interactions, $\pi-\pi$ interactions and steric congestion, the relative organization of these dissymmetric $\pi$-systems in these $\pi$-stacked dimers is difficult to predict and rationalize but is clearly related to the optimization of numerous intra- and intermolecular $\pi-\pi$ interactions (Figure 7a). In turn, these head-to-tail dimers aggregated within infinite columnar $\pi$-stacks in a similar way to what was observed in the case of the $\pi$-stacked compact metallacycles (Figure $6)^{41}$

Even though these new 'U-shape' $\pi$-stacked supramolecular assemblies are not compact metallacycles, their structures mimic the intra- and intermolecular organization encountered in the $\pi$-stacked compact metallacycles described in the previous section. The formation of a cyclic supramolecular structure is therefore not mandatory to obtain such $\pi$-stacked extended assemblies. Therefore a careful examination of the specific factors controlling the formation of a compact supramolecular object (more especially secondary lateral interactions) can give rise to alternative synthetic strategies allowing the rational design of original derivatives. 
a)
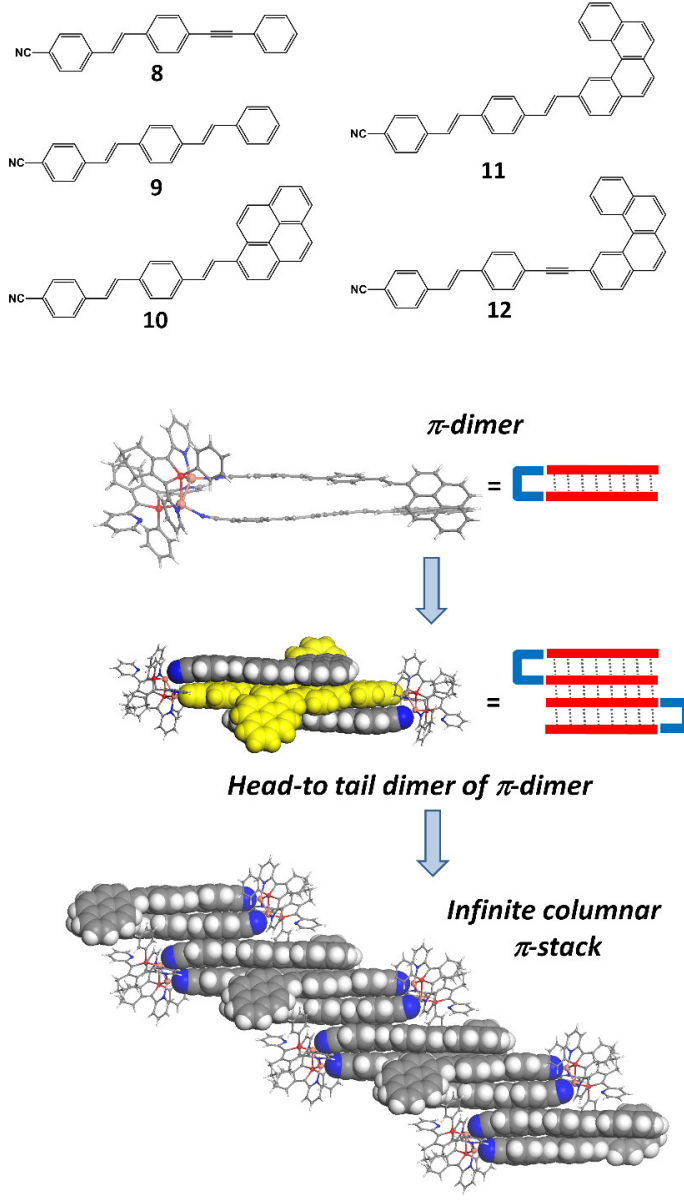

b)

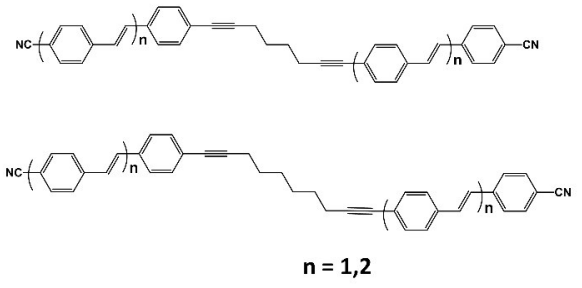

'Pseudo double-paracyclophane' structure

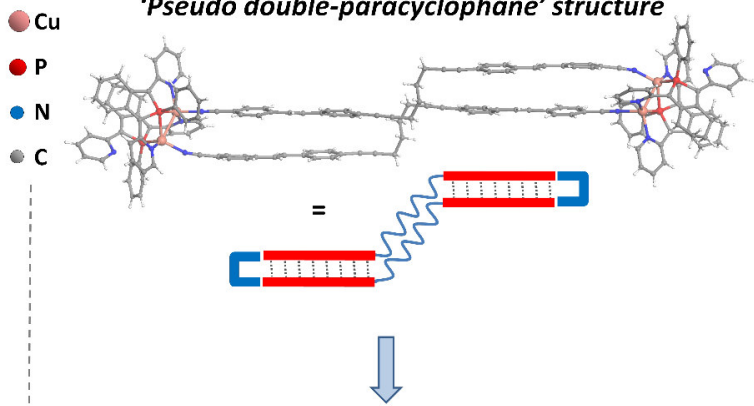

Infinite columns including $\pi$-stacked tetramers

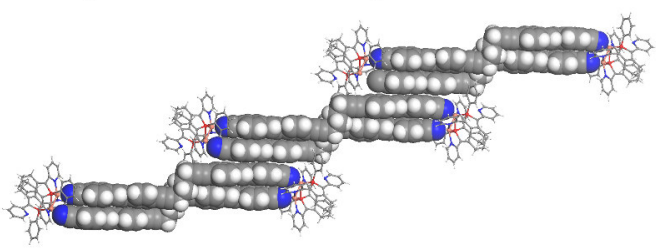

Figure 7. a) Molecular structure of the ligands 8-12; X-ray crystal structure and schematic description of selected U-shape $\pi$-stacked compact supramolecular assembly based on the ligand 10 : $\pi$-stacked dimer, head-to-tail dimer of this $\pi$-dimer, infinite columnar $\pi$-stack; b) Molecular structure of the ditopic linkers bearing central aliphatic flexible fragments and terminal cyano capped rigid $\pi$-conjugated moieties; X-ray crystal structure and schematic description of a selected 'pseudo double-paracyclophane' compact metallacycle.

\section{2 'Pseudo double-paracyclophane' structure}


This assumption is confirmed by the result of the reaction of the molecular clip $\mathbf{2}$ with a series of ditopic linkers bearing central aliphatic flexible fragments and terminal cyano-capped rigid $\pi$ conjugated moieties of various lengths (Figure $7 b$ ). ${ }^{42}$ Due to their intrinsic low rigidity and directionality, such non-directional flexible central cores challenge coordination driven supramolecular chemistry principles as they are supposed to induce lower selectivity and unpredictable reaction products. Unexpectedly, in the case of the coordination of two flexible linkers 13-17 on two $\mathrm{Cu}_{2}(\mathbf{1})_{2}$ moieties, compact $\pi$-stacked metallacycles (Figure $7 \mathrm{~b}$ ) were

formed selectively. ${ }^{42}$ Within these derivatives, intermetallic $\mathrm{Cu}^{\mathrm{I}}$ distances are unchanged and no short contacts are observed between the central aliphatic strings that are mostly parallel with an eclipsed configuration. Conversely, the $\pi$-conjugated moieties of the linkers are involved in intramolecular $\pi-\pi$ interactions with a relative parallel displaced organization. As a result of such arrangement of the ditopic linkers, unprecedented 'pseudo double-paracyclophane' structures (Figure $7 \mathrm{~b}$ ) having large lengths (up to $52.3 \AA$ ) were obtained. ${ }^{42}$ In addition, as observed in the case of the $\pi$-stacked compact metallacycles obtained from fully $\pi$-conjugated linkers (Figure 6 ) and of the 'U-shape' $\pi$-stacked supramolecular assemblies (Figure $7 \mathrm{a}$ ), intermolecular $\pi$ - $\pi$ interactions were also observed in the solid state structure of these compact metallacycles inducing their supramolecular organization in infinite columns bearing discrete stacks of four aromatic moieties separated by imbricated $-\left(\mathrm{CH}_{2}\right)_{\mathrm{n}}$ - fragments (Figure $7 \mathrm{~b}$ ).

\subsection{Folding of a one-dimensional coordination polymer bearing compact supramolecular metallacycles}

The general tendency of $\pi$-stacked compact metallacycles to self-organize in the solid state within extended networks of $\pi$ - $\pi$ interacting $\pi$-conjugated systems can be used in order to 
operate control of the secondary structure of one-dimensional coordination polymers alternating such compact metallacycles in their backbones. The bisphosphole ligand $\mathbf{1 3}$ (Figure 8) in which two N,P,N bis(2-pyridyl)phospholyl moieties are linked by a $p$-phenylene fragment ${ }^{43}$ was reacted with $\mathrm{Cu}^{\mathrm{I}}$ ions affording the tetrametallic complex $\mathbf{1 4}$ bearing two $\mathrm{Cu}^{\mathrm{I}}$ dimers with short intermetallic distances $(\mathrm{d}(\mathrm{Cu}-\mathrm{Cu})=2.5730(8) \AA)$. Within this derivative, no steric strain is generated allowing a free rotation of the two $\mathrm{Cu}^{\mathrm{I}}$ dimer units about the $\mathrm{P}-\mathrm{Ph}-\mathrm{Ph}$ axis. $\mathrm{A}$ 'bis $\mathrm{U}-$ shape molecular clip' " $\mathrm{Cu}_{2}(\mathbf{1 3})(\mathrm{dppm})_{2}$ " can be subsequently generated in-situ from 14 using 1,1bis(diphenylphosphanyl)methane (dppm) as a ancillary ligand on each of the $\mathrm{Cu}^{\mathrm{I}}$ dimers. Reactions with fumaronitrile (as 'short' linker) or with trans-1,2-bis-(4-cyanophenyl)ethylene (as 'long' $\pi$-conjugated linker) afforded new one-dimensional coordination polymers $\mathbf{1 5}$ and $\mathbf{1 6}$ respectively (Figure 8). ${ }^{43}$ Both derivatives presented a similar primary structure with an alternation of compact supramolecular metallacycles connected by $\mathrm{Cu}_{2}(\mathbf{1 3})(\mathrm{dppm})_{2}$ units. Nevertheless, while derivative $\mathbf{1 5}$ displayed a one-dimensional zigzag linear framework, derivative 16 bearing long $\pi$-conjugated linker presented a one-dimensional zigzag folded scaffold (Figure 8). This structural difference resulted from a different relative arrangement of the $\mathrm{Cu}^{\mathrm{I}}$ dimer units relative to the P-Ph-P axe of the ligand $\mathbf{1 3}$ as the 'bis-clip' presented in $\mathbf{1 5}$ an anti conformation while it has a syn arrangement in 16. Indeed, the $\mathrm{Cu}_{2}(\mathbf{1 3})(\mathrm{dppm})_{2}$ 'bis U-shape molecular clip' acted as a molecular 'swivel pin' in the coordination-driven supramolecular assemblies affording these extended structures. This process is driven by the formation of $\pi-\pi$ 'inter-metallacycle' interactions between the $\pi$-stacked compact metallacycles in $\mathbf{1 6}$ (inducing an infinite network of $\pi-\pi$ interactions running all along its one-dimensional skeleton) while the metallacycles in $\mathbf{1 5}$ are isolated from each other. Therefore, formation of compact $\pi$-stacked supramolecular metallacycles can be used as a tool allowing control of the secondary structure of 
coordination polymers bearing $\pi$-conjugated ligands. It is worth noting that this effect mimics the control of the secondary structure of complex biological structures which is most often directed by manifold weak secondary intramolecular interactions that are mostly hydrogen bonds or $\pi-\mathrm{CH}$ interactions.
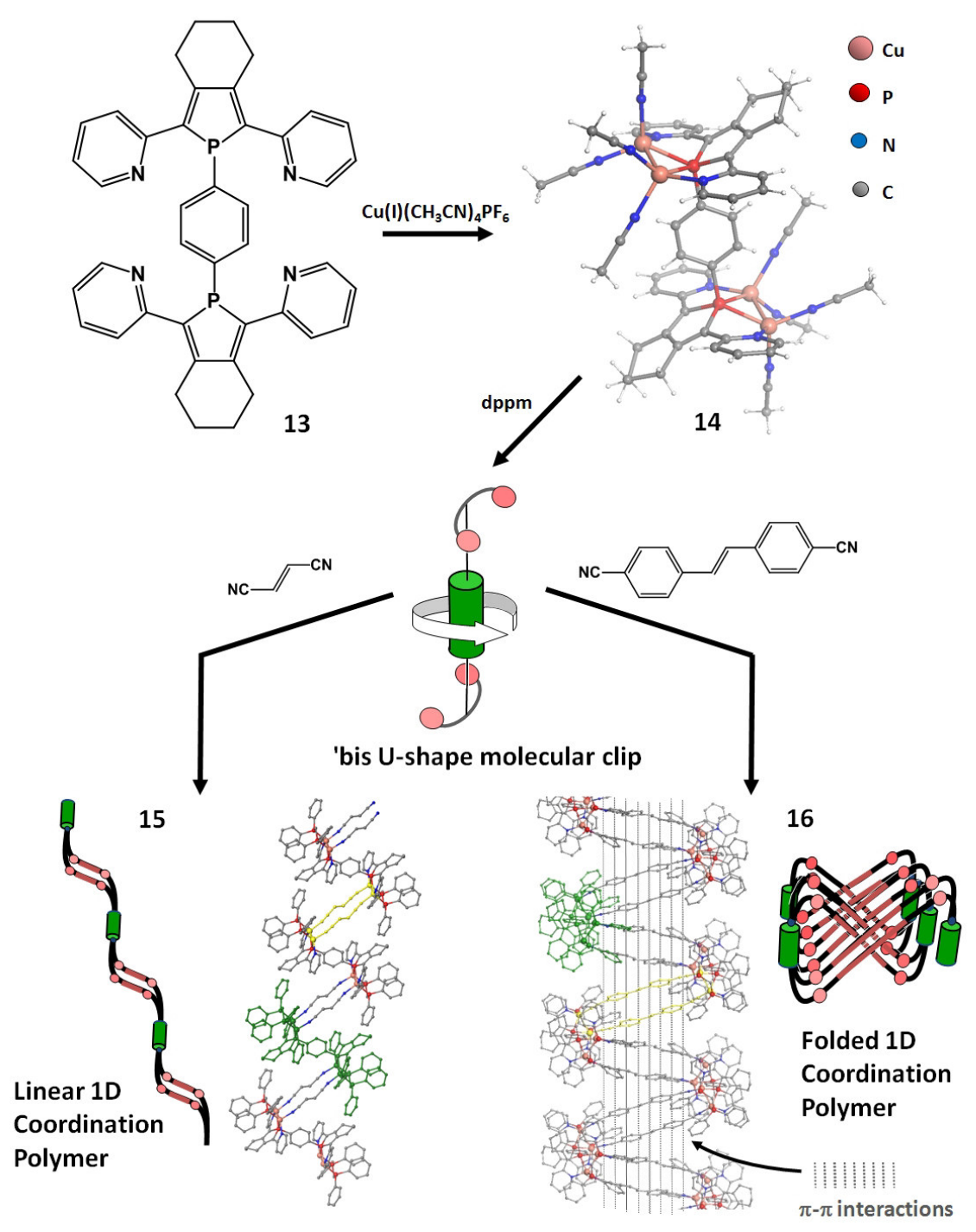

Figure 8. Molecular structure of the ligand $\mathbf{1 3}$ and X-ray crystal structure of the tetracationic complex 14; Schematic description of 'bis U-shape molecular clip' and syntheses, views of the Xray crystal structure and schematic descriptions of the one-dimensional coordination polymers $\mathbf{1 5}$ 
and 16 (H atoms (with the exception of the derivative 14), counter-anions and solvent molecules are omitted; in each X-ray crystal structure view, a compact metallacycle and a $\mathrm{Cu}_{2}(\mathbf{1 3}) \mathrm{dppm}_{2}$ molecular clip are shown, respectively, in yellow and green).

\section{SUMMARY AND PROSPECTUS}

Coordination-driven supramolecular synthesis based on the U-shape molecular clips 2 bearing short intermetallic distances offers a powerful synthetic approach to build selectively compact metallacycles. In turn, particularly in the case of the use of $\pi$-conjugated extended ditopic linkers, these compact metallacycles can act as secondary building blocks to design original discrete or extended $\pi$-networks due to the possible formation of lateral intra- and intermolecular stabilizing interactions. These studies revealed that supramolecular compact metallacycles are set apart from supramolecular hollow metallacycles, both from the point of view of the parameters ruling their selective formation and from the perspective of their use in subsequent supramolecular assembling processes. These results demonstrated that according to a rational design of the individual molecular building blocks, the synthetic rules derived from the 'directional bounding approach' ${ }^{1}$ can be strongly supplemented by the intentional occurrence of non-covalent intramolecular interactions $(\pi-\pi$ interactions or aurophilic interactions) between the assembled subunits. Very interestingly, regarding the current attention paid to solid-state luminescent $\mathrm{Cu}^{\mathrm{I}}$ complexes, ${ }^{44,45}$ this general approach using $\mathrm{Cu}^{\mathrm{I}}$ pre-assembled polymetallic clips may be attractive for the design of new luminescent multifunctional supramolecular materials. ${ }^{46,47}$

\section{AUTHOR INFORMATION}




\section{Corresponding Author}

*E-mail: christophe.lescop@insa-rennes.fr.

Biographical Information

Christophe Lescop was born in Brest, France in 1972. He graduated from the 'Ecole Nationale Supérieure de Chimie de Paris' in 1996 and received his PhD in Chemistry in 2000 from the 'Université de Grenoble 1'. After a post-doctoral stay at the 'Université de Montréal', Canada, he was recruited as a CNRS researcher in 2002 at the 'Institut des Sciences Chimiques de Rennes' UMR 6226 at the University of Rennes 1 and has been hosted since 2016 at INSA-Rennes. His research is focused on coordination chemistry, supramolecular chemistry and multifunctional materials.

\section{Funding Sources}

Financial support from the Centre National de la Recherche Scientifique (CNRS), the Ministère de l'Enseignement Supérieur et de la Recherche, the University of Rennes 1, the Agence Nationale pour la Recherche (ANR) (MetalHel project, ANR Blanc-12-BS07-0004) and the Research Grant Council of Hong Kong (RGC) (P-OPTOELECTR-MOLMAT project, ANRRGC international- ANR-12-IS07-0002), the 'Région Bretagne' (for a Create fellowship), Campus France (for PHC Procope grants) and the Humboldt Foundation (for an Humboldt Fellowship for Experienced Researcher) is greatly acknowledged.

\section{Notes}

The author declares no competing financial interest.

\section{ACKNOWLEDGMENT}

I thank my co-workers: students, postdoctoral fellows, and collaborators whose names appear in the list of references that have greatly contributed to the works that are described in this 
account. Moreover, I would like to acknowledge Pr. Régis Réau, Pr. Vivian W.-W. Yam and Pr. Dr. Manfred Scheer for their positive and meaningful comments and encouragements, which have been a precious source of stimulation in my efforts.

\section{REFERENCES}

(1) Cook, T.R.; Stang, P. J. Recent Developments in the Preparation and Chemistry of Metallacycles and Metallacages via Coordination. Chem. Rev. 2015, 115, 7001-7045.

(2) Harris, K.; Fujita D.; Fujita, M. Giant hollow $M_{n} L_{2 n}$ spherical complexes: structure, functionalisation and applications. Chem. Commun. 2013, 49, 6703-6712.

(3) Chakrabarty, R.; Mukherjee, P. S.; Stang P. J. Supramolecular Coordination: SelfAssembly of Finite Two- and Three-Dimensional Ensembles. Chem Rev. 2011, 111, 6810-6918.

(4) Xu, L.; Wang, Y.-X.; Chen L-J.; Yang, H.-B. Construction of multiferrocenyl metallacycles and metallacages via coordination-driven self-assembly: from structure to functions. Chem. Soc. Rev. 2015, 44, 2148-2167.

(5) Scheer, M. The Coordination Chemistry of Group 15 Element Ligand Complexes - A Developing Area. Dalton Trans. 2008, 4372- 4386.

(6) Han, M.; Engelhard D. M.; Clever, G. H. Self-assembled coordination cages based on banana-shaped ligands. Chem. Soc. Rev. 2014, 43, 1848-1860.

(7) Preston, D.; Barnsley, J. E.; Gordon, K. C.; Crowley J. D. Controlled Formation of Heteroleptic $\left[\mathrm{Pd}_{2}\left(\mathrm{~L}_{\mathrm{a}}\right)_{2}\left(\mathrm{~L}_{\mathrm{b}}\right)_{2}\right]^{4+}$ Cages. J. Am. Chem. Soc. 2016, 138, 10578-10585.

(8) Howlader, P.; Das, P.; Zangrando, E.; Mukherjee P. S. Urea-Functionalized SelfAssembled Molecular Prism for Heterogeneous Catalysis in Water. J. Am. Chem. Soc. 2016, 138, $1668-1676$. 
(9) Mittal, N.; Saha, M. L.; Schmittel, M. Seven-component metallosupramolecular quadrilateral with four different orthogonal complexation vertices. Chem. Commun. 2015, 51, 15514-15517.

(10) Jiang, B.; Zhang, J.; Ma, J. Q.; Zheng, W.; Chen, L. J.; Sun. B.; Li, C.; Hu, B. W.; Tan, H.; Li, X.; Yang, H. B. Vapochromic Behavior of a Chair-Shaped Supramolecular Metallacycle with Ultra-Stability. J. Am. Chem. Soc. 2016, 138, 738-741.

(11) Ronson, T. K.; Pilgrim, B. S.; Nitschke, J. R. Pathway-Dependent Post-assembly Modification of an Anthracene-Edged $\mathrm{M}^{\mathrm{II}}{ }_{4} \mathrm{~L}_{6}$ Tetrahedron. J. Am. Chem. Soc. 2016, 138, $10417-$ 10420.

(12) Chan, A. K-. W.; Wong, K. M-. C.; Yam, V. W-. W. Supramolecular Assembly of Isocyanorhodium(I) Complexes: An Interplay of Rhodium(I) $\cdots$ Rhodium(I) Interactions, Hydrophobic-Hydrophobic Interactions, and Host-Guest Chemistry. J. Am. Chem. Soc. 2015, 137, 6920-6931.

(13 ) Yoshizawa, M.; Klosterman, J.K.; Fujita, M. Functional Molecular Flasks: New Properties and Reactions within Discrete, Self-Assembled Hosts. Angew. Chem. Int. Ed. 2009, $48,3418-3438$.

(14) Northrop, B. H.; Yang H-. B.; Stang, P. J. Coordination-driven self-assembly of functionalized supramolecular metallacycles. Chem. Commun. 2008, 5896-5908.

(15) Wang, W.; Wang, Y-. X.; Yang H-. B. Supramolecular transformations within discrete coordination-driven supramolecular architectures. Chem. Soc. Rev. 2016, 45, 2656-2693.

(16) Fujita, M.; Fujita, N.; Ogura, K.; Yamaguchi, K. Spontaneous assembly of ten components into two interlocked, identical coordination cages. Nature 1999, 400, 52-55. 
(17) Fujii, S.; Tada, T.; Komoto, Y.; Osuga, T.; Murase, T.; Fujita, M.; Kiguchi, M. Rectifying Electron-Transport Properties through Stacks of Aromatic Molecules Inserted into a SelfAssembled Cage. J. Am. Chem. Soc. 2015, 137, 5939-5947.

(18) Mirtschin, S.; Slabon-Turski, A.; Scopelliti, R.; Velders, A. H.; Severin K. A Coordination Cage with an Adaptable Cavity Size. J. Am. Chem. Soc. 2010, 132, 14004-14005.

(19) Yoshizawa, M.; Ono, K.; Kumazawa, K.; Kato, T.; Fujita, M. Metal-Metal d-d Interaction through the Discrete Stacking of Mononuclear $\mathrm{M}(\mathrm{II})$ Complexes $(\mathrm{M}=\mathrm{Pt}, \mathrm{Pd}$, and $\mathrm{Cu})$ within an Organic-Pillared Coordination Cage. J. Am. Chem. Soc. 2005, 127, 10800-10801.

(20) Clever, G. H.; Kawamura, W.; Tashiro, S.; Shiro, M.; Shionoya, M. Stacked Platinum Complexes of the Magnus' Salt Type Inside a Coordination Cage. Angew. Chem. Int. Ed. 2012, $51,2606-2609$.

(21) MacGillivray, L. R.; Papaefstathiou, G. S.; Friščić, T.; Hamilton, T. R.; Bučar, D-. K.; Chu, Q.; Varshney, D. B.; Georgiev, I. G. Supramolecular control of reactivity in the solid state: from templates to ladderanes to metal- organic frameworks. Acc. Chem. Res. 2008, 41, 280-291.

(22) Oliveri, C. G.; Ulmann, P. A.; Wiester, M. J.; Mirkin, C. A. Heteroligated Supramolecular Coordination Complexes Formed via the Halide-Induced Ligand Rearrangement Reaction. Acc. Chem. Res. 2008, 41, 1618-1629.

(23) Castellano, M.; Ruiz-García, R.; Cano, J.; Ferrando-Soria, J.; Pardo, E.; Fortea-Pérez, F. R.; Stiriba, S-. E.; Julve, M.; Lloret, F. Dicopper(II) Metallacyclophanes as Multifunctional Magnetic Devices: A Joint Experimental and Computational Study. Acc. Chem. Res. 2015, 48, $510-520$. 
(24) Mayhan, C. M.; Drachnik, A. M.; Mossine, A. V.; Kumari, H.; Adams, J. E.; Atwood, J. L.; Deakyne, C. A. Metal organic nanocapsules as two-dimensional network building blocks. $J$. Phys. Chem. - C 2016, 120, 13159-13168.

(25) Casanova, M.; Zangrando, E.; Munini, F.; Iengo, E.; Alessio, E. fac- $\left[\operatorname{Re}(\mathrm{CO})_{3}(\mathrm{dmso}-\right.$ $\left.\mathrm{O})_{3}\right]\left(\mathrm{CF}_{3} \mathrm{SO}_{3}\right)$ : a new versatile and efficient $\mathrm{Re}(\mathrm{I})$ precursor for the preparation of mono and polynuclear compounds containing fac- $\left[\operatorname{Re}(\mathrm{CO})_{3}\right]^{+}$fragments. Dalton Trans. 2006, 5033-5045.

(26) Benkstein, K. D.; Hupp, J. T.; Stern, C. L. Synthesis and Characterization of Molecular Rectangles Based upon Rhenium Thiolate Dimers. Inorg. Chem. 1998, 37, 5404-5405.

(27) Dinolfo, P. H.; Williams, M. E.; Stern, C. L.; Hupp, J. T. Rhenium-Based Molecular Rectangles as Frameworks for Ligand-Centered Mixed Valency and Optical Electron Transfer. $J$. Am. Chem. Soc. 2004, 126, 12989-13001.

(28) Puddephatt, R.J. Macrocycles, catenanes, oligomers and polymers in gold chemistry. Chem. Soc. Rev. 2008, 37, 2012-2027.

(29) Leca, F.; Lescop, C.; Rodriguez-Sanz, E.; Costuas, K.; Halet, J-F.; Réau, R. Bridging Phosphanes: Exotic or Versatile Binucleating Ligands? Angew. Chem. Int. Ed. 2005, 44, 43624365.

(30) Nohra, B.; Rodriguez-Sanz, E.; Lescop, C.; Réau, R. Chemistry of Bridging Phosphanes: $\mathrm{Cu}^{\mathrm{I}}$ Dimers Bearing 2,5-Bis(2-pyridyl)phosphole Ligands. Chem. Eur. J. 2008, 14, 3391-3403.

(31) Welsch, S.; Nohra, B.; Peresypkina, E.V.; Lescop, C.; Scheer, M.; Réau, R. Chemistry of Bridging Phosphanes: A Comparative Study within $\mathrm{Cu}^{\mathrm{I}}-\mathrm{Ag}^{\mathrm{I}}-\mathrm{Au}^{\mathrm{I}}$ Triad-Based Homonuclear Dimers. Chem. Eur. J. 2009, 15, 4685-4703.

(32) Vreshch, V.; El Sayed Moussa, M.; Nohra, B.; Srebo, M.; Vanthuyne, N.; Roussel, C.; Autschbach, J.; Crassous, J.; Lescop, C.; Réau, R. Assembly of Helicene-capped N,P,N,P,N- 
helicands within $\mathrm{Cu}^{\mathrm{I}}$-Helicates: Impacting Chiroptical Properties by Ligand-Ligand Charge Transfer. Angew. Chem. Int. Ed. 2013, 52, 1968-1972.

(33) Attenberger, B.; El Sayed Moussa, M.; Brietzke, T.; Vreshch, V.; Holdt, H.-J.; Lescop, C.; Scheer, M. Discrete Polymetallic Arrangements of $\mathrm{Ag}^{\mathrm{I}}$ and $\mathrm{Cu}^{\mathrm{I}}$ Ions Based on Multiple Bridging Phosphane Ligands and $\pi-\pi$ Interactions. Eur. J. Inorg. Chem. 2015, 18, 2934-2938.

(34) Vreshch, V.; Nohra, B.; Lescop, C.; Réau, R. Synthesis of Small Tetranuclear Cu(I) Metallacycles Based on Bridging Pseudohalogenide Ions. Inorg. Chem. 2013, 52, 1496-1503.

(35) Vreshch, V.; Shen, W.; Nohra, B.; Yip, S-K.; Yam, V.W-W.; Lescop, C.; Réau, R. Aurophilicity versus Mercurophilicity: Impact of $\mathrm{d}^{10}-\mathrm{d}^{10}$ Metallophilic Interactions on the Structure of Metal-Rich Supramolecular Assemblies. Chem. Eur. J. 2012, 2, 466-477.

(36) Nohra, B.; Réau, R.; Lescop, C. Insights About the Mechanism of the Formation of Supramolecular $\pi$-Stacked Rectangles Based on $\mathrm{Cu}^{\mathrm{I}}$ Bimetallic Complexes Bearing a Bridging Phosphane Ligand. Eur. J. Inorg. Chem. 2014, 10, 1788-1796.

(37) Nohra, B.; Graule, S.; Lescop, C.; Réau, R. Mimicking [2,2]Paracyclophane Topology: Molecular Clips for the Coordination-Driven Cofacial Assembly of $\pi$-Conjugated Systems. $J$. Am. Chem. Soc. 2006, 128, 3520-3521.

(38) Feng, X.; Marcon, V.; Pisula, W.; Hansen, M.; Kirkpatrick, J.; Grozema, F.; Andrienko, D.; Kremer, K.; Müllen, K. Towards high charge-carrier mobilities by rational design of the shape and periphery of discotics. Nat. Mater. 2009, 8, 421-426.

(39) Golling, F. E.; Quernheim, M.; Wagner, M.; Nishiuchi, T.; Mullen, K. Concise Synthesis of 3D $\pi$-Extended Polyphenylene Cylinders. Angew. Chem. Int. Ed. 2014, 53, 1525-1528. 
(40) Yao, Y.; Shen, W.; Nohra, B.; Lescop, C.; Réau, R. Coordination-Driven Hierarchical Organization of $\pi$-Conjugated Systems: From Molecular to Supramolecular $\pi$-Stacked Assemblies. Chem. Eur. J. 2010, 16, 7143-7163.

(41) El Sayed Moussa, M.; Guillois, K.; Shen, W.; Réau, R.; Crassous, J.; Lescop, C. Dissymmetrical U-Shaped $\pi$-Stacked Supramolecular Assemblies by Using a Dinuclear $\mathrm{Cu}^{\mathrm{I}}$ Clip with Organophosphorus Ligands and Monotopic Fully $\pi$-Conjugated Ligands. Chem. Eur. J. 2014, 20, 14853-14867.

(42) Shen, W.; El Sayed Moussa, M.; Yao Y.; Lescop, C. Supramolecular metallacycles with a 'pseudo double-paracyclophane' structure based on flexible $\pi$-conjugated linkers. Chem. Commun. 2015, 51, 11560-11563 ; Shen, W.; El Sayed Moussa, M.; Yao Y.; Reau R.; Lescop. C. Correction: Supramolecular metallacycles with a 'pseudo double-paracyclophane' structure based on flexible $\pi$-conjugated linkers. Chem. Commun. 2015, 51, 15079-15079.

(43) Agou, T.; Sebastian, M.; Lescop, C.; Réau, R. Folding of a Supramolecular Framework Based on a Tetrametallic Clip Driven by $\pi-\pi$ Interactions. Inorg. Chem. 2011, 50, 3183-3185.

(44) Yam, V. W.-W.; Au, V. K.-M.; Leung, S. Y.-L. Light-Emitting Self-Assembled Materials Based on $\mathrm{d}^{8}$ and $\mathrm{d}^{10}$ Transition Metal Complexes. Chem. Rev. 2015, 115, 7589-7728.

(45) Czerwieniec, R.; Leitl, M. J.; Homeier, H.H.H.; Yersin, H. Thermally $\mathrm{Cu}^{\mathrm{I}}$ Complexes Thermally activated delayed fluorescence. Photophysical approach and material design. Coord. Chem. Rev. 2016, 325, 2-28.

(46) El Sayed Moussa, M.; Evariste, S.; Wong, H.-L.; Le Bras, L.; Roiland, C.; Le Polles, L.; Le Guennic, B.; Costuas, K.; Yam, V. W.-W.; Lescop, C. Solid State Highly Emissive Cu Metallacycle: Promotion of Cuprophilic Interactions at the Excited States. Chem. Commun. 2016, 52, 11370-11373. 
(47) The pre-assembled bimetallic complex 2 as well as the supramolecular assemblies described herein present no luminescent properties in the solid state and in solution (probably due to low-lying molecular orbitals localized on the extended $\pi$-conjugated system of the assembling ligand). 